\title{
Fibroid with unilateral streak ovary in Mullerian Agenesis! A rare case report
}

\author{
Renuka Malik*, Avani Goyal, Meenakshi Bhardawaj
}

Department of Obstetrics and Gynecology, of Obstetrics and Gynaecology, Dr RML Hospital and PGIMER, New Delhi, India

Received: 24 May 2018

Accepted: 26 June 2018

\section{*Correspondence:}

Dr. Renuka Malik,

E-mail: renucam@yahoo.co.in

Copyright: (c) the author(s), publisher and licensee Medip Academy. This is an open-access article distributed under the terms of the Creative Commons Attribution Non-Commercial License, which permits unrestricted non-commercial use, distribution, and reproduction in any medium, provided the original work is properly cited.

\begin{abstract}
Mayer-Rokitansky-Kuster-Hauser (MRKH) syndrome is a rare anomaly (1/5000) associated with uterine and vaginal aplasia with normal ovaries. A fibroid in a normal uterus is common but a fibroid arising from rudimentary horn in Mayer-Rokitansky-Kuster-Hauser (MRKH) syndrome is very rare. It is also rare to have the association of unilateral ovarian dysgenesis in MRKH. A 37 year old married female with primary amenorrhea presented to the OPD of Dr. RML Hospital with abdominopelvic mass for one year. She was phenotypically normal looking and there was no other associated cardiac, ocular or skeletal abnormality. A large $15 \times 15 \mathrm{~cm}$ abdominopelvic mass was present in suprapubic area which was firm in consistency and non-tender. A Two and a half inch long blind vaginal pouch was present with absence of cervix and uterus. A provisional diagnosis of solid ovarian tumor in MRKH syndrome was made. Her investigations -Serum FSH, LH, estradiol and tumor markers were normal. Her ultrasound and MRI reported a fibroid with normal ovaries. Laparotomy revealed absence of uterus and cervix and a large fibroid arising from right rudimentary horn with left streak ovary. Right ovary was enlarged to $4 \times 4 \mathrm{~cm}$, showing multiple small follicles. Fibroid along with the rudimentary horns and the streak ovary was removed, preserving the normal right ovary. Histopathology confirmed the diagnosis of leiomyoma in rudimentary horn with left streak ovary, making it class1 type b anomaly under American fertility society classification. Preoperative assessment of rare anomalies can be different from intraoperative findings in certain female reproductive tract anomalies. Awareness of rare combinations can help in judicious management of such cases.
\end{abstract}

Keywords: Leiomyoma, Mullerian agenesis, Primary amenorrhea, Streak ovary

\section{INTRODUCTION}

Congenital anomalies of the Mullerian system are common defect, reported in up to $3.2 \%$ of all women. The prevalence of congenital uterine anomalies appears to be $6.7 \%$ in fertile population, and it is found in $7.3 \%$ of an infertile population. ${ }^{1}$

Occurrence of a myoma arising from a mullerian remnant is an extremely rare finding and only few cases reported in literatures. ${ }^{1-6}$ The incidence of associated urologic abnormalities ranges between 15-40\%, and skeletal anomalies such as congenital fusion or absence of vertebra occur in approximately $12-50 \%$ of cases. Unilateral renal anomalies are associated with $50 \%$ of the patients. $^{7,8}$

Concurrent association of leiomyoma with Mullerian agenesis with presence of unilateral streak ovary can be a diagnostic dilemma as embryological development of ovary is from genito urinary ridge and of uterus is from paramesonephric duct (Mullerian duct). 


\section{CASE REPORT}

A 37-year married female presented to Gynecological OPD of Dr. RML Hospital and PGIMER on 20 November 2017 with complaints of a gradually increasing abdominal lump for past one year. She also gave history of primary amenorrhea and dysparenuea. She had been married for 18 years and cohabiting since then. She had a 10-year-old adopted daughter. There were no associated urinary or bowel complaints. On examination her height was $165 \mathrm{~cm}$, and weight $40 \mathrm{~kg}$. There was no facial dysmorphism, no features suggestive of Turner syndrome like webbing of the neck or wide carrying angle. Breasts were tanner stage 3 . Pubic and axillary hair were present stage 4 . There were no other associated cardiac, ocular or skeletal abnormality. There was $15 \times 15 \mathrm{~cm}$, firm, and non-tender abdominopelvic mass (Figure 1).

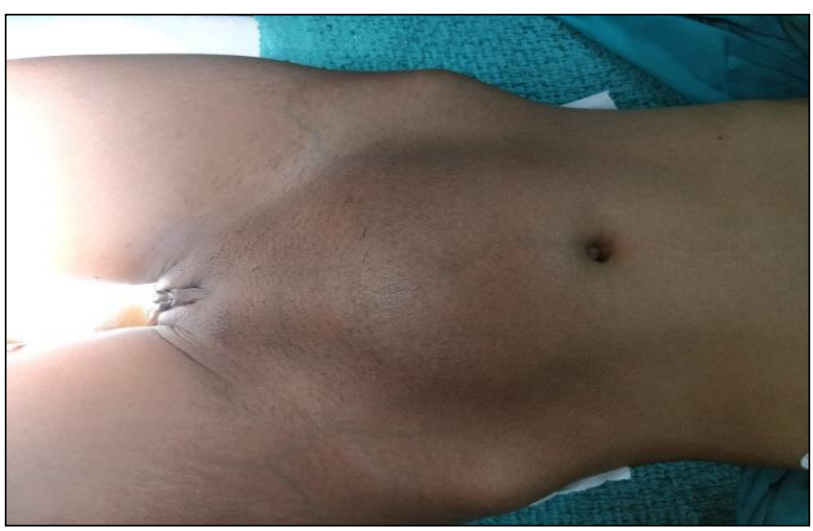

Figure 1: Abdominopelvic mass.

External Genitalia was normal. A two and a half inch long blind vaginal pouch was seen with absent cervix and uterus, confirmed by per vaginal and per rectal examination (Figure 2). Same mass was felt superior to the blind vaginal pouch.

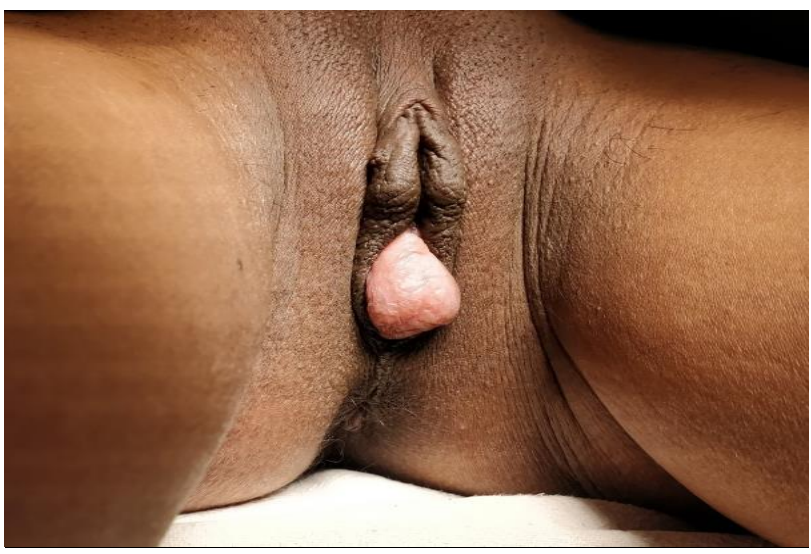

Figure 2: Blind vaginal pouch.

A provisional diagnosis of solid ovarian tumor was made. Her investigations are shown in Table 1.
Table 1: Investigations.

\begin{tabular}{|c|c|c|c|}
\hline Investigation & Result & $\begin{array}{l}\text { Normal } \\
\text { value }\end{array}$ & Inference \\
\hline Serum FSH & $7.52 \mathrm{miu} / \mathrm{ml}$ & $\begin{array}{l}4.5-21.5 \\
\mathrm{miu} / \mathrm{ml}\end{array}$ & Normal \\
\hline Serum LH & $13.70 \mathrm{miu} / \mathrm{ml}$ & $\begin{array}{l}9.6-74.24 \\
\mathrm{miu} / \mathrm{ml}\end{array}$ & Normal \\
\hline LDH & $157 \mathrm{u} / \mathrm{ml}$ & $120-246 \mathrm{u} / \mathrm{ml}$ & Normal \\
\hline AFP & $0.67 \mathrm{iu} / \mathrm{ml}$ & $0.5-5.5 \mathrm{iu} / \mathrm{ml}$ & Normal \\
\hline Ca125 & $6 \mathrm{u} / \mathrm{ml}$ & $0-35 \mathrm{u} / \mathrm{ml}$ & Normal \\
\hline$\beta \mathrm{HCG}$ & $<1.2 \mathrm{miu} / \mathrm{ml}$ & $<5 \mathrm{miu} / \mathrm{ml}$ & Normal \\
\hline Buccal smear & & \multicolumn{2}{|c|}{ Positive for Barr body } \\
\hline Karyotype & $46 x x$ & & \\
\hline
\end{tabular}

Pelvic USG reported a solid tumor possibly of ovarian origin with a hypoplastic uterus. MRI documented a 13.5 $\times 11.2 \times 8.2 \mathrm{~cm}$ whorled structure likely fibroid with normal ovaries and normal kidneys (Figure 3 ).

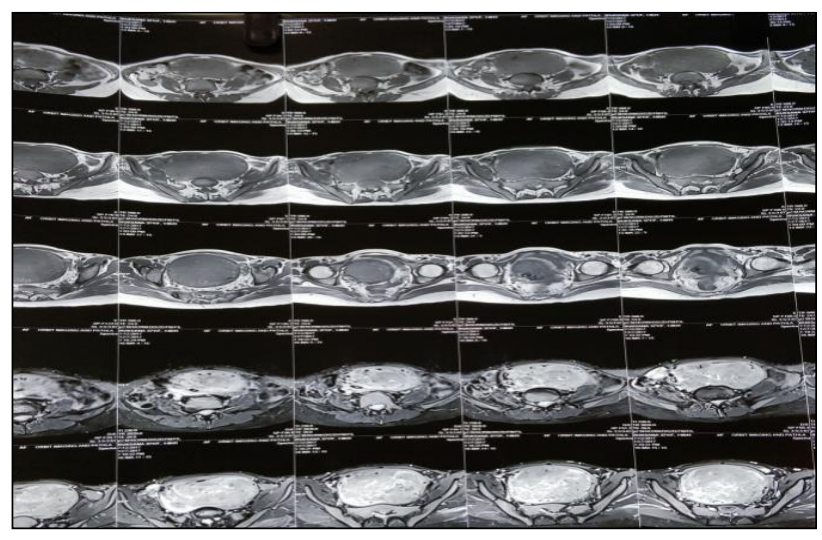

Figure 3: MRI suggestive of leiomyoma with no renal anomaly.

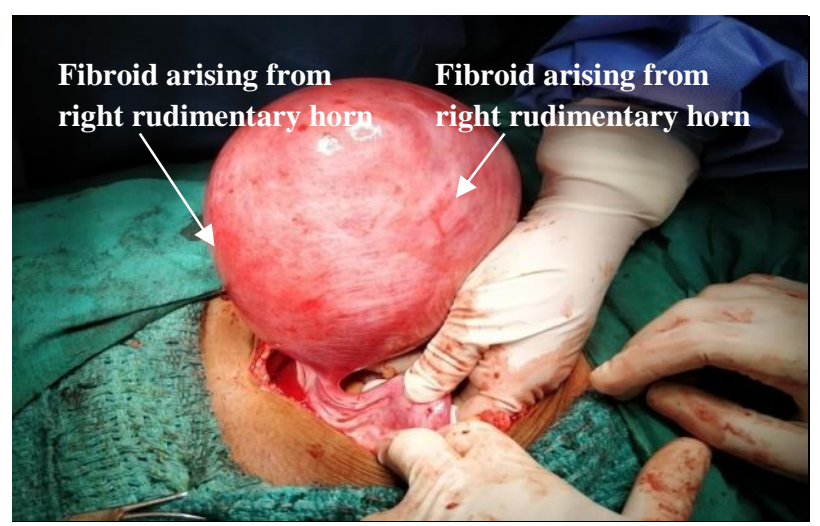

Figure 4: Fibroid and left rudimentary horn.

With a provisional diagnosis of MRKH syndrome associated with ovarian tumor, she was taken up for laparotomy under general anesthesia. Per operatively cervix was absent and a large fibroid of $15 \times 15 \mathrm{~cm}$ was seen originating from right rudimentary horn of the uterus. Right ovary was enlarged to $4 \times 4 \mathrm{~cm}$, with 
multiple small follicles. Close to left rudimentary horn was a streak ovary $5 \times 5 \mathrm{~mm}$ in size (Figure 4-7).

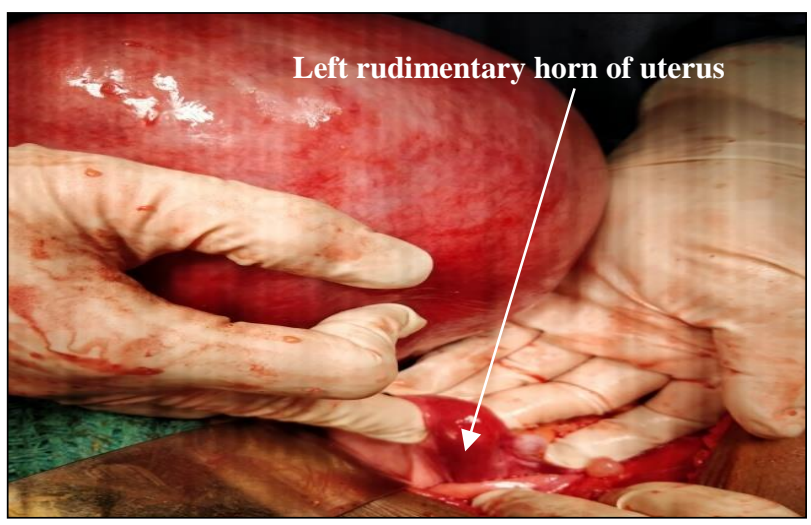

Figure 5: Left rudimentary horn of uterus.

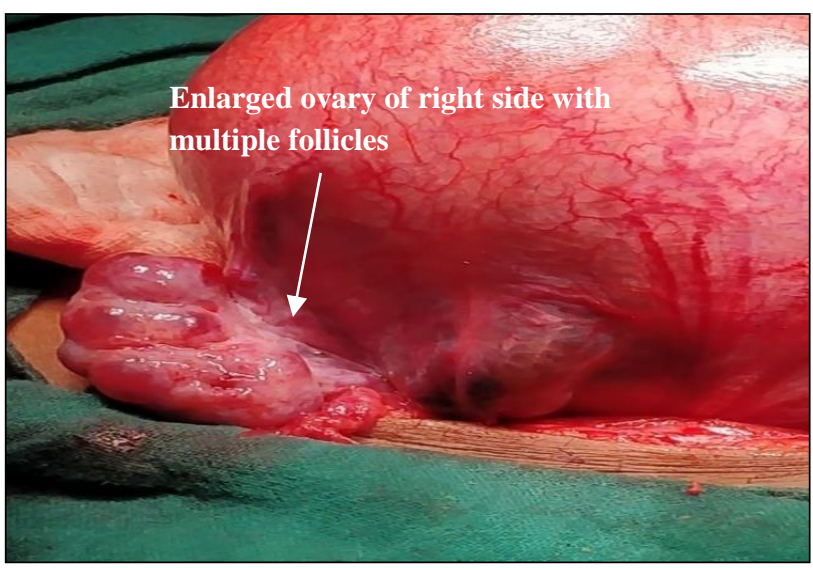

Figure 6: Enlarged right ovary.

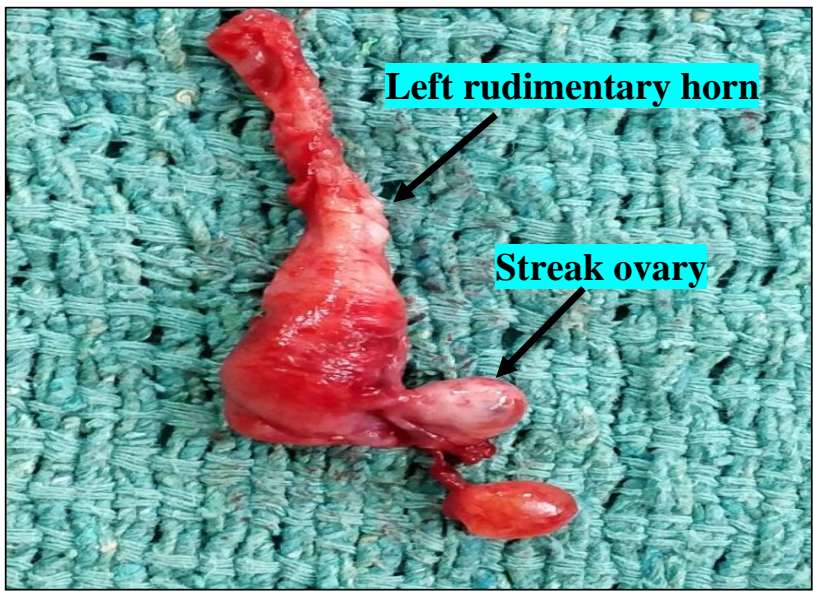

Figure 7: Left rudimentary horn with streak ovary.

No definite tubes could be identified both sides. Fibroid along with the rudimentary horns and the streak ovary was removed, preserving the normal right ovary. On cut section, the mass was firm and had a whorled appearance (Figure 8).

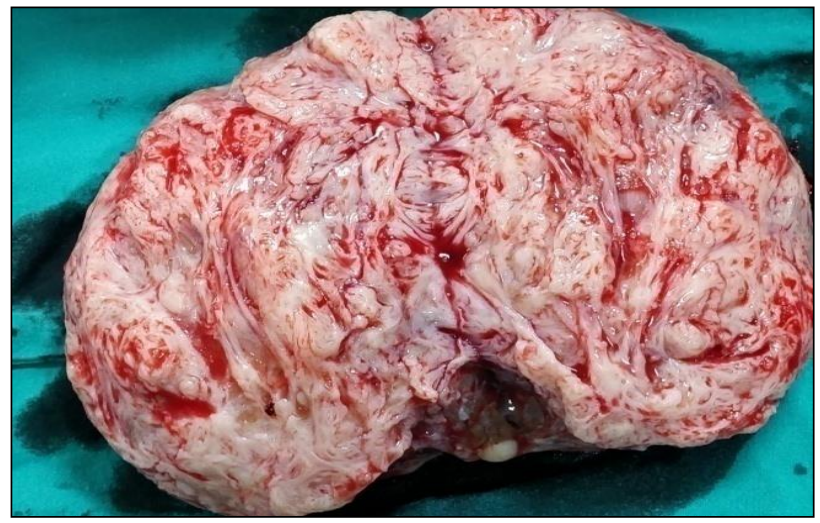

Figure 8: Cut section of the fibroid.

Histopathology confirmed the diagnosis of leiomyoma with left streak ovary, making it class 1 type b anomaly under American fertility society classification. Written informed consent was taken from patient for publication of case and images.

\section{DISCUSSION}

MRKH syndrome is characterized by congenital absence of uterus and upper $2 / 3^{\text {rd }}$ of vagina. The occurrence of leiomyoma which is a smooth muscle tumor in a patient of MRKH syndrome is a possibility though rare occurance. Although Mullerian ducts are primarily mesodermal in origin some smooth muscle may occur at their proximal ends which may be the origin of leiomyoma. In MRKH syndrome usually tubes and ovary are normal but rarely can be absent or dysgentic suggesting a multifactorial cause in development of this syndrome.

The female reproductive tract develops from two embryologic structures: Mullerian duct and urogenital sinus (UGS). The Mullerian or paramesonephric duct (PMD) ducts are mesodermal in origin and UGS is endodermal in origin. The development of urinary system is closely related to reproductive system hence their anomalies are closely associated.

The paired PMD of Müllerian ducts that form the following structures: fallopian tube, uterus, cervix and the upper two-thirds of the vagina. The ovaries and lower third of the vagina have different embryological origins derived from germ cells that migrate from the primitive yolk sac and the sinovaginal bulb, respectively.

Normal development of the Müllerian ducts depends on the completion of three phases: organogenesis, fusion and septal resorption. At 6 weeks of development, in female embryo, the paired PMD initially separated by a septum fuse and form a Yshaped structure uterovaginal primordium (UVP). The UVP and UGS thereafter form female reproductive system. The American Fertility Society (AFS) classification, based on uterine anomalies, is most commonly used to classify Mullerian duct 
anomalies. Anomalies of vagina, tubes and urinary tract are described as associated malformations. This classification system comprises of seven classes:

- I - uterine hypoplasia and agenesis

- II - unicornuate uterus

- III - uterus didelphys

- IV - bicornuate uterus

- V - septate uterus

- VI - arcuate uterus

- VII - diethylstilbestrol (DES)-related anomalies.

They have been subdivided into typical or type A and atypical or typeB, when malformations in the ovary or renal system are present and MURCS (Müllerian aplasia, renal aplasia, and cervicothoracic somite dysplasia) association, when malformations are in the skeleton, heart and renal system. ${ }^{7-10}$

MRKH syndrome is a class I Mullerian duct anomaly. Our case was class 1, type B anomaly with associated leiomyoma and bilateral absent tubes and unilateral ovarian dysgenesis. There was no associated chromosomal or skeletal or renal anomaly in our patient.

The etiology of MRKH Syndrome is elusive at present. It has been considered for a long time as an occasional anomaly but the literature supports the assumption that a specific genetic substratum exists. An autosomal dominant pattern with variable expressivity and genetic mutations in WNT 4, LHX1 and HNF1 B have been implicated in occurrence of MRKH syndrome. ${ }^{10}$ As ovarian function is normal, secondary sexual characters are well developed and estrogen-dependent pathological conditions can develop in the rudimentary uterus, including myomas, neoplasm and adenomyosis.

There are very few cases of leiomyoma reported in women with MRKH syndrome and rarer are reports of unilateral ovarian dysgenesis associated with MRKH syndrome. ${ }^{1-6,11-13}$ Differential diagnosis of leiomyoma of rudimentary uterus in MRKH syndrome includes ovarian fibroma, gastrointestinal stromal tumor (GIST) of intestine and extravesical leiomyoma of urinary bladder. The uncommon occurrence of leiomyoma in MRKH may be explained by decreased concentration or sensitivity of estrogen receptors in the rudimentary tissue.

MRI has nearly $100 \%$ accuracy in diagnosis of Mullerian duct anomalies because of its excellent soft tissue resolution. Uterus and vagina are best evaluated on T2weighted sagittal and axial MR images. Diagnostic laparoscopy remains the gold standard for definitive diagnosis of MRKH syndrome.

\section{CONCLUSION}

The association of fibroid in MRKH should be kept in mind as although a rare occurrence but leiomyoma can develop from the rudimentary horn. Association of ovarian dysgenesis with this syndrome points towards multifactorial etiology. Knowledge of rare combinations in Mullerian tract anomalies can help in diagnosing and management of such cases.

Funding: No funding sources

Conflict of interest: None declared

Ethical approval: Not required

\section{REFERENCES}

1. Girma W, Wondimagegnehu W. Leiomyoma arising from mullerian remnant, mimicking ovarian tumor in a woman with mrkh syndrome and unilateral renal agenesis. Ethiop J Health Sci. 2015;25(4):381-4.

2. Hoo P, Norhaslinda A, Reza J. Rare case of leiomyoma and adenomyosis in Mayer-RokitanskyKuster-Hauser syndrome. Case Rep Obstet Gynecol. 2016;2016:1-4.

3. Rawat KS, Buxi T, Yadav A, Ghuman SS, Dhawan S. Large leiomyoma in a woman with MayerRokitansky-Kuster-Hauser syndrome. J Radiol Case Rep. 2013;7:39-46.

4. Singh S, Chakrawarty B, Chakarawarty M. A large fibroid arising from mullerian bulb mimicking ovarian tumour in a woman with MRKH. Int $\mathbf{J}$ Infertility Fetal Med. 2012;3(1):30-2.

5. Samani EN, Fallahian M. Leiomyoma arising from rudimentary uterus: a case Report. Iranian J Pathol. 2007;2(4):187-89.

6. Kulkarni MM, Deshmukh SD, Hol K, Nene N. A rare case of Mayer-Rokitansky-Kuster-Hauser syndrome with multiple leiomyomas in hypoplastic uterus. J Hum Reprod Sci. 2015;8:242-4.

7. Oppelt P, Renner SP, Kellermann A, Brucker S, Hauser GA, Ludwig KS, et al. Clinical aspects of Mayer-Rokitansky-Kuester-Hauser syndrome: recommendations for clinical diagnosis and staging. Hum Reprod. 2006;21(3):792-7.

8. Morcel K, Camborieux L, Guerrier D. MayerRokitansky-Küster-Hauser (MRKH) syndrome. Orphanet J Rare Dis. 2007;2:13.

9. Adhesions A. The American Fertility Society classifications of adnexal adhesions, distal tubal occlusion, tubal occlusion secondary to tubal ligation, tubal pregnancies, Mullerian anomalies and intrauterine adhesions. Fertil Steril. 1988;49(6):944.

10. Pizzo A, Laganà A, Sturlese E, Retto G, Retto A, De Dominici R, et al. Mayer-Rokitansky-Kuster-Hauser Syndrome: embryology, genetics and clinical and surgical treatment. ISRN Obstet Gynecol. 2013;2013:1-10.

11. Ting TC, Chang SP. Coexistence of gonadal dysgenesis and Mullerian agenesis with two mosaic cell lines 45, X/46, X, del (X)(p22. 2). Chinese Med J TAIPEI. 2002;65(9):450-2.

12. Dede M, Gezginç K, Ulubay M, Alanbay I, Yenen M. A rare case of rudimentary uterus with absence of both ovaries and 46, xx normal karyotype without 
mosaicism. Taiwanese J Obstet Gynecol. 2008;47(1):84-6.

13. Shah V, Ganatra P, Parikh R, Kamdar P, Baxi S, Shah N. Coexistence of gonadal dysgenesis and Mayer-Rokitansky-Kuster-Hauser syndrome in 46,
XX female: a case report and review of literature. Indian J Endocrinol Metabol. 2013;17(7):274.

Cite this article as: Malik R, Goyal A, Bhardawaj M. Fibroid with unilateral streak ovary in Mullerian Agenesis! A rare case report. Int J Reprod Contracept Obstet Gynecol 2018;7:3392-6. 